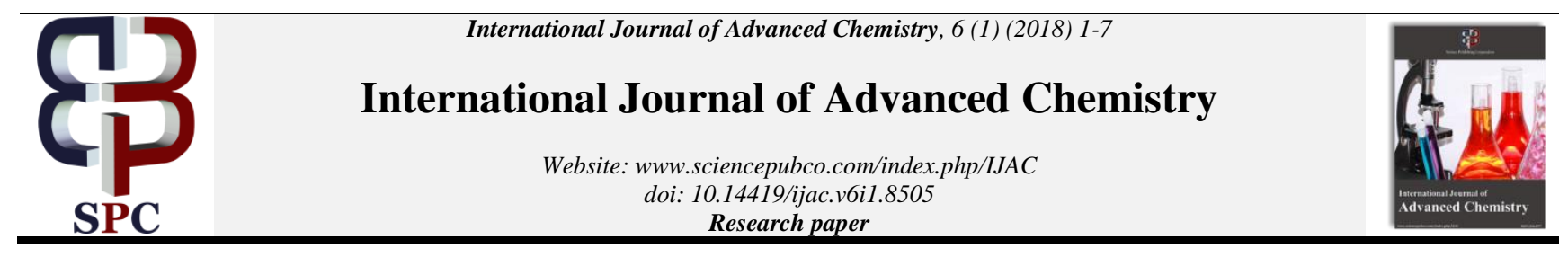

\title{
Characterization of commercial detergents and natural cleansing agents with comparison of their potential for biodegradability
}

\author{
Anjali Mer, Rajesh Samant *, Prabha Padmanabha \\ Department of Chemistry and Department of Microbiology, K. C. College, D. W. Road, Churchgate, Mumbai: 400020, India \\ *Corresponding author's E-mail: samantrajesh@yahoo.co.in
}

\begin{abstract}
Background: Commercial detergents are chemical formulations designed to dissolve or disperse grease, grime, and dirt by making them water soluble or suspending it in water. They are best known for their wide use in laundry industry and household cleaning. After use, the wash waters along with the residual detergents are discharged into sewage system and are carried to water bodies, which result in damaging the biodiversity of aquatic environment due to the non-degradable nature of the active detergent matter present in these cleansing agents.

Method: A critical analytical study was conducted on the quality of popular detergent powders sold in the Indian market viz. Ariel, Surf Excel, Rin and Tide with respect to their moisture content, active and total alkalinity, active detergent matter, water-insoluble matter, oxygen releasing capacity and $\mathrm{pH}$. Two natural cleansing agents viz. Areetha and Shikakai were tested for the same parameters. Bacterial cultures were isolated from detergent-rich soil in Dhobighat, Mumbai and used to study detergent degradation over a period of time. Methylene Blue Photometric Assay was used to estimate the reduction in active detergent matter.

Result and Conclusion: Areetha and Shikakai were found effective as detergents but with certain limitations. Degradation was seen in the commercial detergents over a period of time.
\end{abstract}

Keywords: Biodegradation; Detergents; Methylene Blue Photometric Assay.

\section{Introduction}

Detergents, by definition are anything that cleans; which include soaps, synthetic detergent powders and liquids, alkaline materials, solvents etc. But popularly, the term 'detergent' is used for packaged cleansing products added to water for household laundry (Synthetic Detergents in Perspective - their relationship to sewage disposal and safe water supplies, The Soap and Detergent Association, New York). Laundry detergent or washing powder is a type of detergent (cleaning agent) that is added for cleaning laundry. The mixtures of chemical compounds that include alkyl benzene sulfonates, which are similar to soap but are less affected by hard water, are commonly used for the manufacturing of detergents.

\subsection{Utilization of detergents}

The synthetic detergent industry is a profitable industry due to the need for laundry and cleaning by every individual considering the increasing world population (Smulders et al. 2012). The commercial sector is enlarging its market share rapidly by increasing the influence on consumers with the help of mass media. The detergent market has grown into a highly competitive one, where various vivid brands grapple to get consumers' recognition. Each brand claims to clean spotlessly and brighter, employing technologically questionable phrases like fighting granules, dirt gravitator etc. Large quantities of surfactants are being used in household and industries daily, and most of which disseminate in soil and water (Abayomi \& Omoniyi, 2013). Surfactants are usually the largest contributor of artificial organic carbon to the aquatic ecosystem. The sewage treatments in countries like India are extremely poor, and the use of detergents is increasing exponentially. (Siwiński et al.1998). In India, the detergent sector in the laundry care industry has grown from INR 57 billion in 2003 to INR 130 billion in 2011, registering a growth of $\sim 11 \%$ during the period. It is estimated, that the industry would reach levels of INR 241 billion by 2017 ("Market Research Report on Detergent Industry in India” NPCS, 2014).

\subsection{Adverse effects of detergents}

Detergents being used on large scale and their poor sewage treatment are responsible for its toxic effects on aquatic animals such as fishes and microbes like yeasts and bacteria (Singer et al. 1992, Feisthauer et al. 2004). Eutrophication, commonly known as nutrient pollution, is also a pressing issue caused by excessive deposition of surfactants in freshwater bodies. Aquatic plants like algae use the readily available nutrients like phosphorous, nitrogen and carbon from the detergents, which rapidly cause algal blooms. This in turn led to a decrease in the concentration of dissolved oxygen in water. This creates hypoxic and anoxic conditions killing fish, producing foul odour and increasing the anaerobic pathogenic flora (Huddleston et al. 1963).

Constant exposure to detergents is also dangerous to mammals, including humans (Fendinger et al. 1994). A study conducted to 
perceive the Indian consumers' conditions due to the adverse effects of detergents on health, showed that $77.6 \%$ of subjects had experienced some kinds of skin irritation due to the detergent use and the major population among them, comprised of washer men and rural women. The primary reason for health problems is due to conventional laundry detergents that leave chemical residues on clothes, which enter the human body via the skin or through the lungs. The usual result of a steady and intemperate exposure of the skin to detergents is drying, fissuring and dotting of the keratin layer leading to increased permeability that causes sensitization, which may develop into dermatitis.

Elderly people are more susceptible to infections that may lead to developing eczema. Other health problems could be allergies, skin infections and in rare cases, cancer as detergent may contain carcinogens (Yuan et al. 2014). The fragrances used in laundry detergents can trigger allergies and may aggravate the lungs, causing serious health effects to people with asthma or chronic heart problems (Huddleston et al. 1963). Detergents are also partly responsible for the decline of coastal plants subjected to polluted spray; the cloudy water phenomenon, i.e. formation of large foam ponds due to excessive foaming in rivers and for the contamination of groundwater by contributing nutrients and mineral salts such as phosphates, nitrates, ammonium, boron, etc. (Payne 1963, Payne et al. 1965, Fannin et al. 1981) Due to these growing complications, some form of bioremediation of detergents is a necessity.

\subsection{Biodegradability of detergents}

Biodegradability is simply defined as the breakdown of an organic substance to simpler substances (carbon dioxide, water, methane or other simple organic molecules) by micro-organisms (bacteria, fungi) or other biological means. The rate of biodegradation depends on $\mathrm{pH}$, temperature, oxygen, microbial population, degree of acclimation, accessibility of nutrients, chemical structure of compound, cellular transport properties, and chemical portioning in the growth medium (Fannin et al. 1981)

A number of bacterial species are known to degrade surfactants and most of them are isolated from contaminated soil, water or sediments. Many aerobic bacterial species have the potential to degrade surfactants in the peptone mediums gratuitously, but very few species grow in a defined medium with surfactant as a sole carbon/energy source (Goodnow et al. 1972).

\section{Methods}

Four brands of marketed detergent powders were procured from the open market in India, and taken up for the study of commercial detergents.

\begin{tabular}{|c|c|c|c|}
\hline Brand name & Manufactured by & Barcode No. & $\begin{array}{l}\text { Date of } \\
\text { Packing }\end{array}$ \\
\hline \multirow{2}{*}{ Ariel } & Procter \& Gamble & 4 & Packed \\
\hline & Company, Mumbai & 902430651783 & on $9 / 15$ \\
\hline Surf Excel & Hindustan Unilever & 8 & Packed \\
\hline (Quick wash) & Ltd. (HUL), Mumbai & 901030515927 & on $7 / 15$ \\
\hline $\begin{array}{l}\text { Rin } \\
\text { (Whites like } \\
\text { new) }\end{array}$ & $\begin{array}{l}\text { Hindustan Unilever } \\
\text { Ltd. (HUL), Mumbai }\end{array}$ & $\begin{array}{l}8 \\
901030454301\end{array}$ & $\begin{array}{l}\text { Packed } \\
\text { on } 3 / 15\end{array}$ \\
\hline $\begin{array}{l}\text { Tide Plus } \\
\text { (Jasmine and } \\
\text { Rose) }\end{array}$ & $\begin{array}{l}\text { Procter \& Gamble } \\
\text { Company, Mumbai }\end{array}$ & $\begin{array}{l}4 \\
902430653176\end{array}$ & $\begin{array}{l}\text { Packed } \\
\text { on } 7 / 15\end{array}$ \\
\hline
\end{tabular}

The powdered seeds of Areetha (Sapindus trifoliatus) and Shikakai (Acacia concinna) were taken up for the purpose of studying natural detergents.

\subsection{Moisture content}

About $1 \mathrm{~g}$ of the material was weighed accurately into a dry tarred dish, and dried to a constant mass in a hot air oven at a temperature of $105 \pm 1^{\circ} \mathrm{C}$. It was cooled in a desiccator and was weighed.
Moisture content $=(\mathrm{M}-\mathrm{m}) * 100 / \mathrm{M}$

$\mathrm{M}=$ mass in $\mathrm{g}$ of the material taken for the test and $\mathrm{m}=$ mass in $\mathrm{g}$ of the material after drying

\subsection{Alkalinity}

$25 \mathrm{ml}$ of stock sample solution was pipetted out and titrated against $0.1 \mathrm{~N} \mathrm{HCl}$, till it became colourless (using Phenolphthalein as Indicator), that burette reading was taken as ' $\mathrm{A} \mathrm{ml}$ ' for determining Active Alkalinity. For the same solution, titration was continued with $0.1 \mathrm{~N} \mathrm{HCl}$, till the colour changed from yellow to orangish red (using Methyl Orange as indicator), that burette reading was taken to be ' $\mathrm{B}$ ml' for determining Total Alkalinity.

Active alkalinity $(\mathrm{x})=\mathrm{A} * 0.1 * 31 / 1000 \mathrm{~g}$ of $\mathrm{Na}_{2} \mathrm{O}$

Total alkalinity $(\mathrm{y})=\mathrm{B} * 0.1 * 31 / 1000 \mathrm{~g}$ of $\mathrm{Na}_{2} \mathrm{O}$

\subsection{Active detergent matter}

$10 \mathrm{ml}$ of sample was pipetted out. $10 \mathrm{ml}$ of chloroform and $5 \mathrm{ml}$ of $0.005 \%$ methylene blue solution was added to it. It was shaken well. The chloroform layer (lower) was coloured blue. The mixture was then titrated with addition of $0.5 \mathrm{ml}$ standardized cetrimide solution at a time. After each addition, the titrand was shaken well and the phases were allowed to separate. Initially the chloroform phase was coloured blue. Towards the end, the colour started migrating to the aqueous layer. The reading which had the colour intensity equivalent in both the phases was noted

$\mathrm{x} \mathrm{ml}$ of $0.002 \mathrm{M}$ Cetrimide $=\mathrm{x} * 0.002 * 348 / 1000 \mathrm{~g}$ of SLS

\subsection{Water insoluble impurity}

A $\mathrm{G}_{4}$ grade crucible was weighed and was fitted to a Buchner flask, to which suction was applied. $1 \%$ sample solution was poured through a sintered glass filter funnel. The residue was dried in a hot air-oven at a temperature of $105 \pm 2{ }^{\circ} \mathrm{C}$. It was cooled in a desiccator and weighed till constant mass was obtained.

Matter insoluble impurity $=100(\mathrm{~m} / \mathrm{M})$

$\mathrm{m}=$ mass in $\mathrm{g}$ of the matter insoluble in water, and $\mathrm{M}=$ mass in $\mathrm{g}$ of the sample taken for the test.

\subsection{Oxygen releasing capacity}

$50 \mathrm{ml}$ of $1 \%$ solution was pipetted out in conical flask. To this, 1 test tube of $\mathrm{HCl}$ was added and titrated against $0.1 \mathrm{~N} \mathrm{KMnO}_{4}$ till faint pink colour persisted.

$\mathrm{x} \mathrm{ml}$ of $\mathrm{O} .1 \mathrm{~N} \mathrm{KMnO}_{4}=8 * 0.1 * \mathrm{x} / 1000$ of $\mathrm{O}_{2}$ in $50 \mathrm{ml}$

\section{6. $\mathrm{pH}$}

$1 \pm 0.001 \mathrm{~g}$ of the material was weighed and transferred to a 100 $\mathrm{ml}$ volumetric flask. The flask was partially filled with distilled water and agitated until the sample was completely dissolved. The solution was filtered through Whatman filter paper: 41, in case of residual solids. The temperature of the solution and the distilled water was adjusted to $30 \pm 0.5^{\circ} \mathrm{C}$; the volume was made up to the calibration mark with distilled water. The flask was stoppered, mixed thoroughly, and the solution was allowed to stand at a temperature of $30^{\circ} \mathrm{C}$ for two hours before measuring the $\mathrm{pH}$. The $\mathrm{pH}$ of the solution was measured using a glass electrode.

\subsection{Biodegradation of synthetic detergents}

\subsubsection{Source of bacterial sample and collection}


Soil from the outlet of laundry washing water from Dhobighat, a commercial laundry cleaning area in Mahalaxmi, Mumbai, Maharashtra, India was collected in sterile containers, stored at $4^{\circ} \mathrm{C}$ till processed and serially diluted. This served as the source of detergent-degrading bacteria. The bacteria were isolated on Nutrient Agar plates supplemented with a synthetic detergent. Gram nature and colony characteristics of two bacterial isolates were studied.

\subsubsection{Cultivation of isolated bacterial cultures}

Isolated bacteria was sub-cultured on sterile Nutrient Agar slant and M9 media supplemented with a synthetic detergent and incubated at $37^{\circ} \mathrm{C}$ for 48 hours to screen its degradative capacity. The $48-72$ hour cultures were suspended in sterile saline and set to 0.1 O.D.at $540 \mathrm{~nm}$.

\subsubsection{Sterilization of detergent sample}

$1 \mathrm{~g}$ of detergent samples viz. Ariel, surf excel, Rin and Tide were weighed, packed in packets and was put in a dry hot air oven for sterilization.

\subsubsection{Inoculation of bacterial sample}

2.7.4.1. Sterile M9 media (incomplete mineral medium) was used as growth media to check for the 2 bacterial cultures' capability to use detergent as a primary source of carbon.

2.7.4.2. Sterile $250 \mathrm{ml}$ conical flask labelled as $1,2,3,4,5,6,7,8$, 9 and 10 were filled with $100 \mathrm{ml}$ sterile saline. Flask 1, 3, 4, 5 and 6 was inoculated with $1 \mathrm{ml}$ mix culture of the two types of organisms. Flasks 3, 4, 5, 6, 7, 8, 9 and 10 contained $1 \mathrm{~g}$ of surfactant.

\section{Results and Discussion}

\subsection{Moisture content}

Table 1: Moisture content of various detergents

\begin{tabular}{lll}
\hline Sr. No. & Sample & Moisture content $(\%)$ \\
\hline 1. & Ariel & 2.639 \\
2. & Surf Excel & 6.312 \\
3. & Rin & 2.320 \\
4. & Tide & 2.881 \\
5. & Areetha & 6.390 \\
6. & Shikakai & 6.395 \\
\hline
\end{tabular}

As shown in Table 1, only Surf Excel has $6.312 \%$ moisture which is equal to $6.39 \%$ moisture in both the natural products (Areetha and Shikakai). One can understand the presence of moisture in natural products, but if commercial criteria are adopted, it becomes difficult to justify the moisture content in Surf Excel.

\subsection{Alkalinity}

Table 2.1: Active alkalinity of various detergents

\begin{tabular}{|c|c|c|c|c|}
\hline \multirow[b]{2}{*}{ Sr. No. } & \multirow[b]{2}{*}{ Sample } & \multicolumn{3}{|c|}{ Active Alkalinity $\left(\mathrm{mg} \mathrm{Na}_{2} \mathrm{O}\right)$} \\
\hline & & $\begin{array}{l}\text { Fresh } \\
\text { Sample }\end{array}$ & $\begin{array}{l}\text { After } 15 \\
\text { days }\end{array}$ & $\begin{array}{l}\text { After } 30 \\
\text { days }\end{array}$ \\
\hline 1. & Ariel & 8.06 & 8.99 & 10.51 \\
\hline 2. & Surf Excel & 10.23 & 10.85 & 11.56 \\
\hline 3. & Rin & 5.58 & 6.51 & 7.71 \\
\hline 4. & Tide & 7.13 & 7.44 & 6.66 \\
\hline
\end{tabular}

Table 2.2: Total alkalinity of various detergents

\begin{tabular}{lllll}
\multicolumn{4}{c}{ Table 2.2: Total alkalinity of various detergents } \\
\hline \multirow{3}{*}{ Sr. No. } & Sample & Fresh & After 15 & $\begin{array}{l}\text { After } 30 \\
\text { days }\end{array}$ \\
& & Sample & days & dalinity $\left(\mathrm{ma}_{2} \mathrm{O}\right)$ \\
\hline 1. & Ariel & 16.43 & 18.91 & 21.37 \\
2. & Surf Excel & 19.22 & 20.46 & 22.47 \\
3. & Rin & 13.33 & 12.71 & 15.41 \\
4. & Tide & 14.57 & 13.33 & 14.36 \\
5. & Areetha & 2.17 & 1.24 & 1.75 \\
6. & Shikakai & 1.55 & 3.72 & 2.45 \\
\hline
\end{tabular}

The alkaline nature of the detergents is a key determinant of its effectiveness as a cleansing agent. Oil or grease can be removed from the cloth only in alkaline conditions; also mild alkaline conditions make the hard water soft and improve the detergency action. Effectiveness in hard water is the advantage that detergents have over soap. The alkalinity of a detergent is measured in terms of active alkalinity (or bicarbonate alkalinity) and total alkalinity (or carbonate alkalinity). Active alkalinity helps in water softening and total alkalinity helps in the removal of oil and grease.

As the detergents are predominantly non-biodegradable, it is expected to show the same alkalinity after a long span of time when they are disposed in water. Hence, the known concentrations of detergent solutions were preserved in an open container (beaker) for about a month. The same procedure was followed, and readings were taken after 15 days and 30 days from the date of preparation. The results obtained for the Active and Total alkalinities of the samples are reported in Table 2.1 and Table 2.2. The graphical representation of data is given in Fig. 1 and Fig. 2.

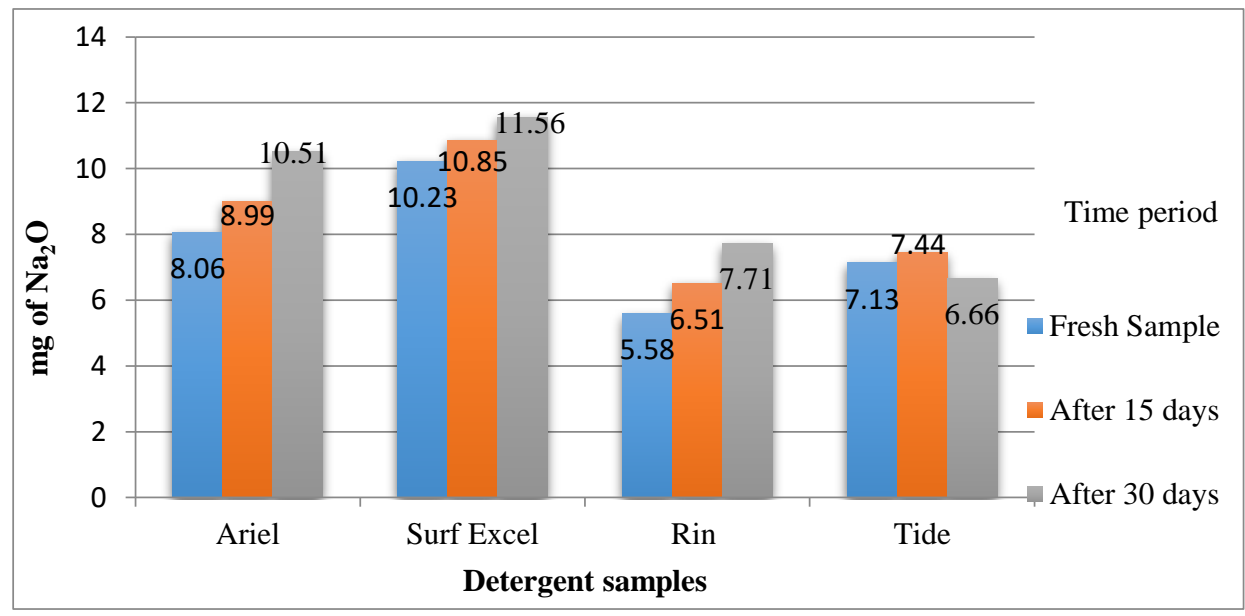

Fig. 1: Active alkalinity of detergent samples. 


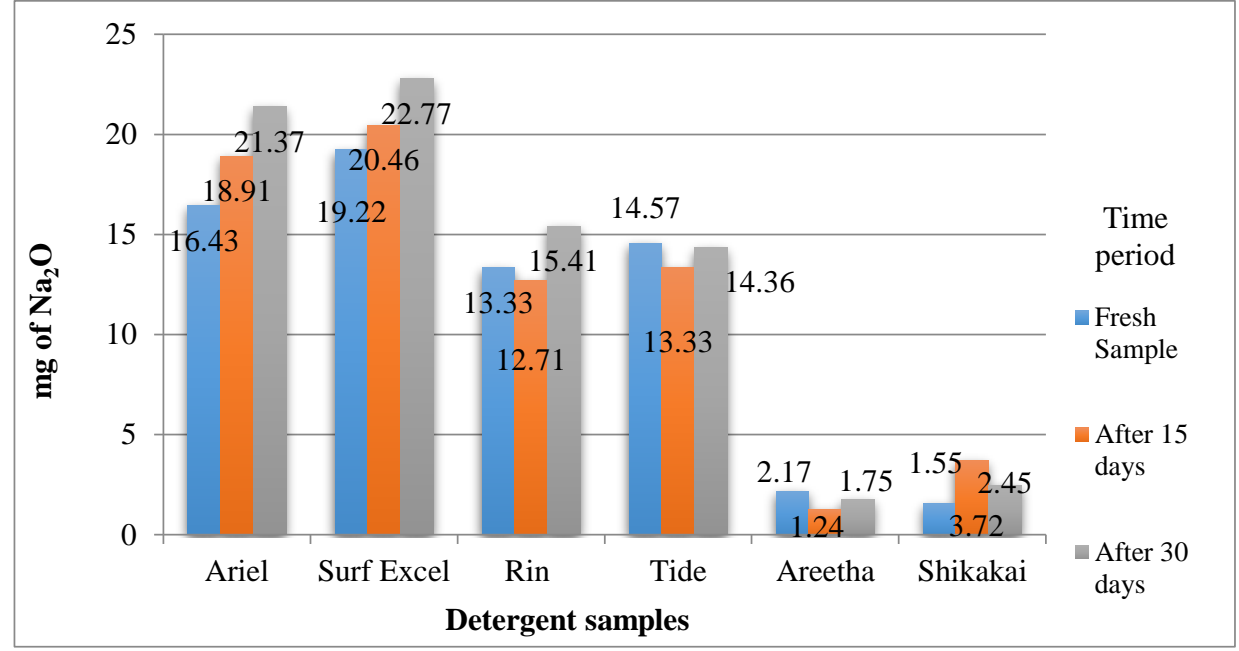

Fig. 2: Total alkalinity of detergent samples.

\subsection{Active detergent matter}

Table 3: Active detergent matter of the samples of various detergents.

\begin{tabular}{lllll}
\hline & & \multicolumn{3}{l}{ Active detergent matter (mg of SLS) } \\
Sr. No. & Sample & $\begin{array}{l}\text { Fresh } \\
\text { Sample }\end{array}$ & $\begin{array}{l}\text { After 15 } \\
\text { days }\end{array}$ & $\begin{array}{l}\text { After 30 } \\
\text { days }\end{array}$ \\
\hline 1. & Ariel & 18.792 & 18.742 & 16.704 \\
2. & Surf Excel & 24.012 & 24.36 & 20.88 \\
3. & Rin & 15.66 & 16.008 & 13.92 \\
4. & Tide & 15.98 & 16.704 & 14.964 \\
\hline
\end{tabular}

The activity of a detergent varies with its active detergent matter content like Sodium Lauryl Sulphate. The effectiveness of a detergent can be easily correlated with the active detergent matter. As it is known that the detergents are predominantly non-biodegradable, this indicates that Sodium Lauryl Sulphate remains unaffected in the solution for a longer time.

The solutions once prepared were kept for one month in an open atmosphere and the measurements were carried out for the active detergent matter on the first, $15^{\text {th }}$ and the $30^{\text {th }}$ day. The results obtained are shown in Table 3 and represented graphically in Fig. 3. As the natural detergents had no Sodium Lauryl Sulphate, it could not be detected in any case of sample and period.

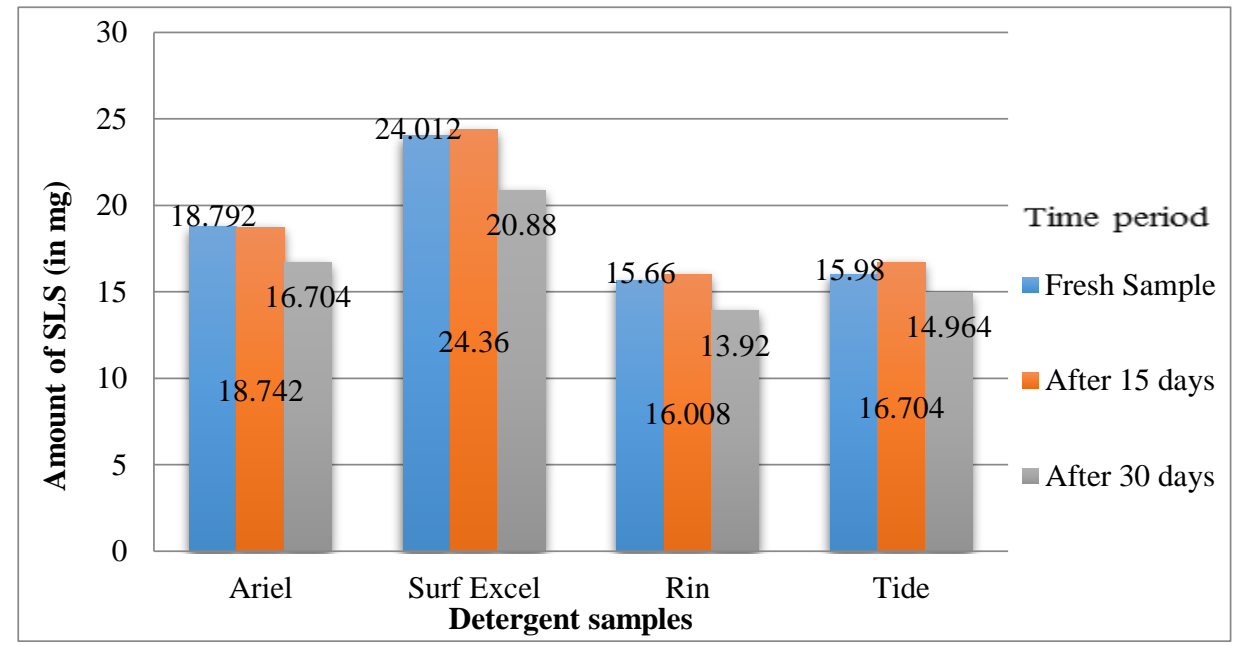

Fig. 3: Active detergent matter of the samples of various detergents.

\subsection{Water insoluble impurity}

Table 4: Insoluble matter in various detergents

\begin{tabular}{lll} 
& \multicolumn{2}{l}{ Table 4: Insoluble matter in various detergents } \\
\hline Sr. No. & Sample & Insoluble matter $(\%)$ \\
2. & Ariel & 14.24 \\
3. & Surf Excel & 16.80 \\
4. & Rin & 1.72 \\
5. & Tide & 0.56 \\
6. & Areetha & 47.80 \\
\hline
\end{tabular}

As the detergents are non-degradable, the insoluble matter in the detergents remains in water body for a long time. This has made determination of the insoluble matter of detergents a point of interest. The amount of insoluble matter in the various detergent samples is shown in Table 4.

\subsection{Oxygen releasing capacity}

Table 5: Oxygen releasing capacity of various detergents

\begin{tabular}{lll}
\hline Sr. No. & Sample & Oxygen releasing capacity $(\mathrm{ppm})$ \\
\hline 1. & Ariel & 14.40 \\
2. & Surf Excel & 8.00 \\
3. & Rin & 4.80 \\
4. & Tide & 3.20 \\
5. & Areetha & 128.00 \\
6. & Shikakai & 176.00 \\
\hline
\end{tabular}

Nascent oxygen generally used for bleaching/cleaning of the cloth. The property of releasing oxygen has given detergents a tremendous advantage over soaps. The detergent which releases more oxygen is considered to be better detergent. The results of oxygen releasing capacity of all the samples are reported in the Table 5. 


\section{6. $\mathrm{pH}$}

Table 6: $\mathrm{pH}$ of Fresh $1 \%$ Solutions of various detergents

\begin{tabular}{lll}
\hline Sr. No. & Sample & $\mathrm{pH}$ \\
\hline 1. & Ariel & 10.26 \\
2. & Surf Excel & 10.27 \\
3. & Rin & 10.16 \\
4. & Tide & 10.12 \\
5. & Areetha & 6.59 \\
6. & Shikakai & 6.51 \\
\hline
\end{tabular}

The alkalinity of detergent solutions has already been discussed. Although the relevance of $\mathrm{pH}$ of the solutions remains immaterial for this analysis, $\mathrm{pH}$ parameter of the $1 \%$ solution of the sample is taken to have data for correlation. The results of $\mathrm{pH}$ of all the samples are reported in the Table 6.

\subsection{Biodegradation of synthetic detergents}

\subsubsection{Isolation and cultivation of detergent degrading bacteria}

Two bacterial strains of detergent degrading bacteria were isolated from detergent rich soil in Dhobighat, Mahalaxmi, Mumbai, Maharashtra, India. This place was selected because it is a commercial area for the washer men for washing of clothes. Using enrichment technique, the isolates were inoculated in nutrient media supplemented with detergent. The plates were incubated in at $37^{\circ} \mathrm{C}$. After 2-3 days, when prominent growth was observed, the colony characteristics of the isolates were studied. These isolates recovered from Dhobighat were designated as $\mathrm{C} 1$ and $\mathrm{C} 2$ respectively.

Table 7: Colony Characteristics of Isolates $\mathrm{C} 1$ and $\mathrm{C} 2$

\begin{tabular}{lll}
\hline Characteristics & C 1 & C 2 \\
\hline Size & large & medium \\
Shape & ovoid & circular \\
Colour & colourless & cream \\
Elevation & flat & low convex \\
Margin & entire & entire \\
Opacity & translucent & translucent \\
Gram nature & Gram negative & Gram negative \\
Morphology & coccobacilli & coccobacilli \\
\hline
\end{tabular}

3.6.2. Degradation of active detergent matter by bacterial culture isolated from soil in Dhobighat and quantifying the result using methylene blue photometric assay

The determination of the biodegradation for synthetic detergent samples is crucial in the outcome of the investigation, and this was done using the Methylene Blue Photometric Method. The Methylene Blue Active substance (MBAS) analysis was used to determine the concentration of active detergent matter in each of the commercial detergent products. The mixtures of 2 isolated Gramnegative bacterial cultures were used to study detergent degradation over a period of 30 days. Reduction of absorbance of MBAS was used to estimate the reduction in active detergent matter in the solutions. Degradation was followed over a period of time.

A significant reduction was observed in the absorbance and concentration of MBAS (shown in Table 7. 1. and Table 7. 2. The graphical representation is shown in Figure 7.1 and 7.2) in the 1\% sample detergent solutions viz. Ariel, Surf Excel, Rin and Tide. This indicates that the active detergent matter present in them can be degraded slowly by the bacterial cultures isolated from the detergent rich soil in Dhobighat.

The Figure 7. 3. It gives the percentage degradation of the active detergent matter of the sample detergents, over a span of 15 days, 15 - 30 days and overall degradation in 30 days. Ariel, surf Excel, Rin and Tide are degraded to $86.21 \%, 90.14 \%, 77.88 \%$ and 66.42 $\%$ respectively over 30 days.

Bureau of Indian Standards (BIS) does not enlist the criteria of biodegradability of detergents in I.S.: $4955-2001$.

Whereas, under Environment Protection Authority (EPA) of Australia, the Australian Standard for biodegradability (AS1792 methods to determine the Biodegradability of Surfactants) requires $80 \%$ of the mixture to be degraded within 21 days, to carry the 'biodegradable' label. So according to EPA, except for Ariel, the other sample detergents are non-biodegradable (Method for Determining the Biodegradability of Surfactants, Standard Association of Australia).

Table 7. 1: The Absorbance of MBAS (mg MBAS/L) on Day 1, Day 15 and Day 30 for various detergent samples

\begin{tabular}{llll}
\hline Sample (1\% Detergent solution) & O. D. at 620 nm for Day 1 & O. D. a t620 nm for Day 15 & O. D. at 620 nm for Day 30 \\
\hline Ariel & 0.41 & 0.06 & 0.06 \\
Surf Excel & 0.09 & 0.06 & 0.01 \\
Rin & 0.17 & 0.10 & 0.04 \\
Tide & 0.17 & 0.08 & 0.06 \\
\hline
\end{tabular}

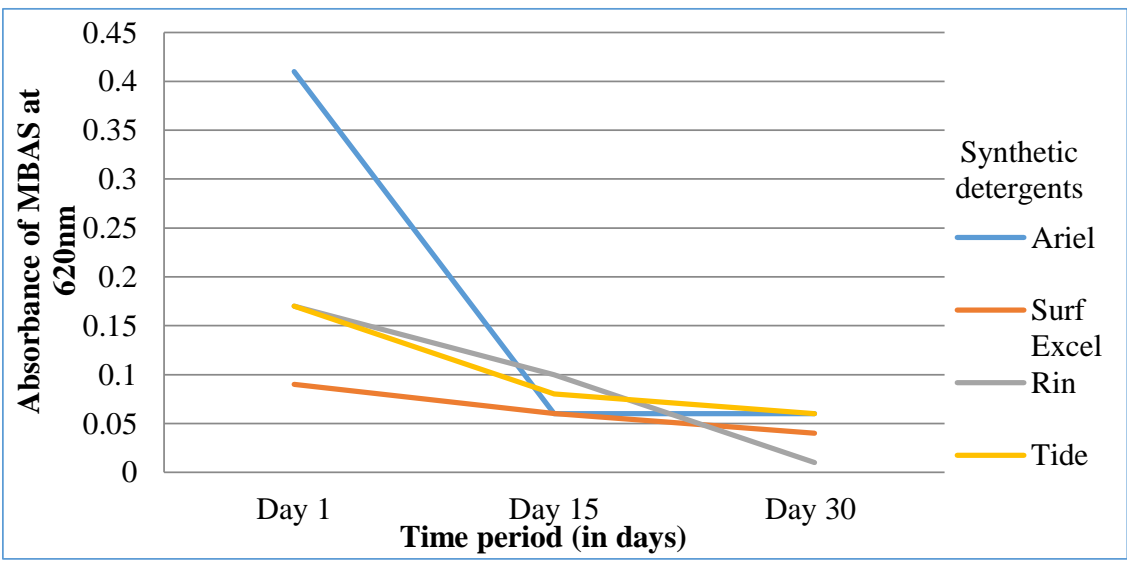

Fig 7. 1: The Absorbance of MBAS (mg MBAS/L) on Day 1, Day 15 and Day 30 for various detergent samples

Table 7. 2: The concentration of MBAS (mg MBAS/L) on Day 1, Day 15 and Day 30 for various detergent samples

\begin{tabular}{llll}
\hline Sample & Concentration of MBAS on Day 1 & Concentration of MBAS on Day 15 & Concentration of MBAS on Day 30 \\
\hline Ariel & 0.682 & 0.094 & 0.094 \\
Surf Excel & 0.142 & 0.094 & 0.014 \\
Rin & 0.280 & 0.160 & 0.062 \\
Tide & 0.280 & 0.126 & 0.094 \\
\hline
\end{tabular}




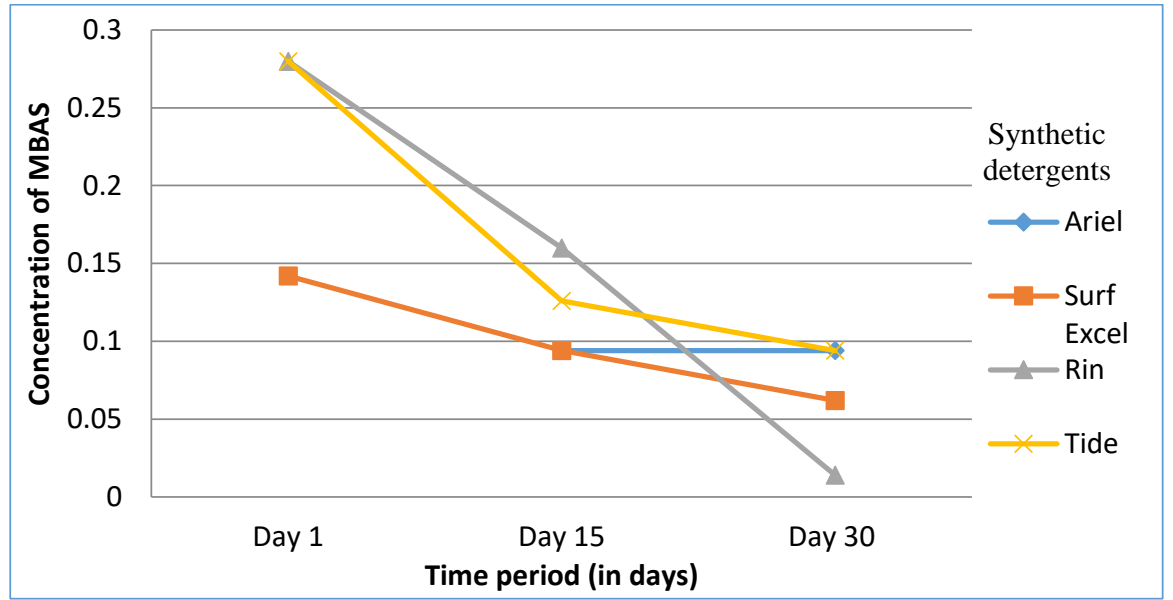

Fig. 7. 2: The concentration of MBAS (mg MBAS/L) on Day 1, Day 15 and Day 30 for various detergent samples

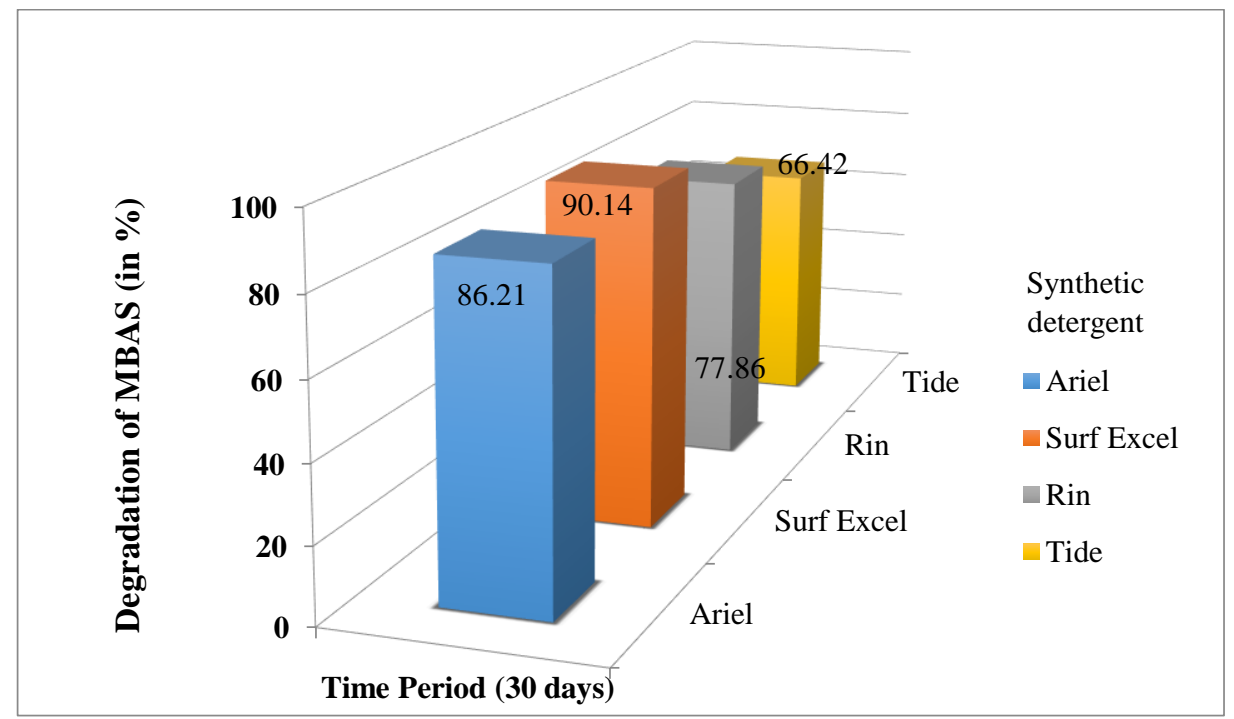

Fig. 7. 3: The Percent Total Degradation of the Sample Synthetic Detergents in 30 Days.

\section{Conclusion}

The purpose of this work was to compare the properties of commercially available detergents viz. Ariel, Surf Excel, Rin, Tide and the natural cleansing agents viz. Areetha and Shikakai. After reviewing the results that were obtained from chemical and microbial analysis, we observed that natural cleansing agents are almost at par with the commercial equivalents. It is an accepted fact that natural cleansing agents do not produce the same results with commercial samples in some tests, but can be made equivalent to the properties of the commercial samples by using minimal quantity of chemical aid.

The moisture in natural cleansing agents is comparatively high, but this could be justified by the process of obtaining the natural samples. The natural samples were obtained by crushing of the seeds directly, but heat drying was not performed in the oven before use. Thus it can be stated that, after heat drying, the moisture content can be lowered, and the other results would have been further improved.

The natural cleansing agents are very mildly alkaline. This has an advantage in washing delicate fibres like wool and other synthetic fibres. The colours of the threads are also secured in the moderately low alkaline detergent solutions, which give natural cleansing agents a distinct advantage over commercial detergents. It will be of further interest to compare the oil / grease removal capacity of natural cleansing agents with specialized commercial detergents.

Pollution control was another agenda behind this study. If the solubility results are reviewed, the natural cleansing agents are not sufficiently soluble in water. If the effluent containing natural cleansing agents is filtered after use, then the insoluble matter can be easily removed. This will help the reduction in load of effluent treatment for removal of Chemical Oxygen Demand (COD) / Biological Oxygen Demand (BOD).

The functioning of the natural cleansing agents is mainly based on its capacity to release the nascent oxygen. Huge amount of oxygen is released by these products; that will indirectly help in reduction of COD in the effluent.

Natural cleansing agents are biodegradable and hence can be removed from the effluent with minimal processing, whereas, the Environment Protection Authority (EPA) requires $80 \%$ of the detergent mixture to be degraded within 21 days. This signifies that the advantage of natural cleansing agents is limited to 21 days, over the commercial detergents.

If some water-soluble softeners and active-detergent matter are added, then we can minimize the deleterious effects of synthetic detergents and greater performance from the natural products can be achieved. The systematic drying and proper packing will improve the performance of the natural materials making a significant impact on the environment.

\section{Acknowledgements}

First and foremost, I would like to express my heartfelt gratitude to God for constantly giving strength to persevere and wisdom to do this research project.

I would like to thank the former principal of K. C. College, Mumbai: Dr. Manjula J. Nichani; the convener of the Science Honours Program: Dr. Sagarika Damle; coordinator of the Science Honours Program: Dr. Anupama Harshal; the former H.O.D. of Chemistry 
Department: Mr. R. C. Moorjani; coordinator of Biotechnology Department: Dr. Sejal Rathod for permitting and providing the facilities, equipments, etc. for my research endeavours.

I would like to pay my regards to my guide: Dr. Rajesh Samant and my co-guide: Mrs. Prabha Padmanabha for their exemplary guidance, monitoring and constant encouragement throughout this project.

I take this opportunity to thank Mr. Kevin Menezes, Director of Every Nation Organization, India for having faith in me and funding this project through ENVision Scholarship program.

I would like to thank the non-teaching staff of Chemistry and Microbiology Department, Dr. Satish Kolte: Assistant Professor of Chemistry and N.S.S. Program Officer; my family, my friends and well-wishers; whose assistance proved to be a milestone in the accomplishment of my end goal.

\section{References}

[1] "Synthetic Detergents in Perspective - their relationship to sewage disposal and safe water supplies". Technical Adisory Council. The Soap and Detergent Association, New York (1962), p. 7.

[2] Eduard Smulders, Wolfgang Rybinski, Eric Sung, Wilfried Rähse, Josef Steber, Frederike Wiebel, Anette Nordskog, "Laundry Detergents" in Ullmann's Encyclopedia of Industrial Chemistry 2002, Wiley-VCH, Weinheim.

[3] Olusola Abayomi and Ojo-Omoniyi (2013): "Biodegradation of Synthetic Detergents", Biodegradation - Life of Science, Dr. Rolando Chamy (Ed.), InTech, https://doi.org/10.5772/56461.

[4] Siwiński P., Szymański A., Łukaszewski Z. (1998): "Biodegradability of Detergent Powder Surfactants in the River Water DieAway Test", Technical University of Poznań, Institute of Chemistry, Piotrowo 3, 60-965 Poznań, Poland

[5] Feisthauer N., Sibley P., Burke S. and Kaushik N. (2004): "A review of the toxicity of detergents and its formulation components on aquatic organisms", International Journal of Ecology and Environmental Science. vol.28, p.223-297.

[6] Singer, M. M. and R. Tjeerdema (1992): "Fate and effects of the surfactant sodium dodecyl sulphate". Rev Environment Contamination Toxicology. 133:95-149 https://doi.org/10.1007/978-1-46139529-4 3.

[7] Huddleston R. L. and Allred R. C. (1963): "Microbial oxidation of sulfonated alkyl benzenes." Developing Indian Microbiology. Vol.4, p.24-37.

[8] Fendinger N., Versteg D., Weeg E., Dyer S., Rapaport R. (1994): "Environmental behavior and fate of anionic surfactants." Environmental Chemistry of Lakes and Reservoirs, American Chemical Society, Washington, DC. P.527-557. https://doi.org/10.1021/ba1994-0237.ch017.

[9] Payne W. J. (1963): "Pure culture studies of the degradation of detergent compounds." Biotechnol. Bioeng. 5:355- 365. https://doi.org/10.1002/bit.260050409.

[10] Payne W. J., Williams J. P., and Mayberry W. R. (1965): "Primary alcohol sulfatase in a Pseudomonas species". Applied Microbiology. 13:698-701.

[11] Fannin T., Marcus M., Anderson D. and Bergmani H. (1981): "Use of a Fractional Factorial Design to Evaluate Interactions of Environmental Factors Affecting Biodegradation Rates", Applied and Environmental Microbiology. Department of

[12] Zoology and Physiology and Department of Statistics, University of Wyoming, Laramie, Wyoming. Vol. 42, p. 936-943.

[13] Goodnow R. and Harrison A. (1972): "Bacterial Degradation of Detergent Compounds", Applied Microbiology, American Society for Microbiology. Division of Biological Sciences, University of Missouri, Columbia, Missouri. Received June 1972. p. 555-560

[14] "Standard Methods for the Examination of Water and Wastewater". American Public Health Association, Washington D. C. (1992) p. 5-36.

[15] "Method for Determining the Biodegradability of Surfactants", Australian Standard 1792-1976. Standard Association of Australia Incorporated by Royal Charter.

[16] "Market Research Report On Detergent Industry In India (Market Size, Opportunities, Comparative Financial Analysis, Demand Supply Scenario, Outlook And Forecasts Upto 2017) by Npcs Team.", NIIR Project Consultancy Services, 2014, www.niir.org/books/book/market-research-report-on-detergentindustry-in-india-market-size-opportunities-comparative-financial- analysis-demand-supply-scenario-outlook-forecasts-upto-2017/isbn 9789381039397/zb,18b73,a,1,0,3e8/index.html

[17] Yuan C. L., Xu Z.Z., Fan M. X., Liu H. Y., Xie Y. H. and Zhu T. (2014): "Study on characteristics and harm of surfactants" Journal of Chemical and Pharmaceutical Research, 6(7):2233-2237

[18] Lewis MA (1990): "Chronic toxicities of surfactants and detergent builders to algae: A review and risk assessment" Exotoxicol. Environ. Safety, Vol. 20(2), p.123. https://doi.org/10.1016/0147$\underline{6513(90) 90052-7 .}$ 